\title{
Do not just sit there, do something ... but do no harm: the worrying aspects of COVID-19 experimental interventions
}

\author{
Mervyn Singer ${ }^{1^{*}}$ (1) and Andre Kalil ${ }^{2}$
}

(C) 2021 Springer-Verlag GmbH Germany, part of Springer Nature

For nearly four decades a multitude of randomised controlled trials have struggled to find a magic bullet for improving sepsis outcomes. We have experienced false dawns such as anti-endotoxin antibody, anti-TNF therapies, activated protein C, early goal-directed therapy, tight glycaemic control and high-dose vitamin $\mathrm{C}$, and have lived through the swinging pendulum of belief or distrust in corticosteroids. Truth be told, we have not seriously progressed beyond the age-old tenets of timely antibiotics [1], source control and restoration of organ perfusion other than recognition of iatrogenic harm through overdoing our interventions, be it excessive ventilation, fluid, catecholamines, corticosteroids, sedation or nutrition [2]. Primum non nocere, first do no harm.

Yet we are belatedly recognising that some of these shelved interventions, not to mention newer targeted therapies, could indeed work in the right patient when delivered at the right time, at the right dose and for the right duration. One size does not fit all. Just as cancer has malignant cells as a defining requirement, sepsis mandates an inappropriate host response to infection. However, both cancer and sepsis are umbrella terms for syndromes that embrace multiple causes, body locations, and patient populations with highly variable clinical presentation and outcomes.

A much-needed paradigm shift over the last decade has advanced the case of identifying which intervention suits a particular patient, in other words a theranosticdriven, personalised approach. Retrospective analyses of

*Correspondence: m.singer@ucl.ac.uk

${ }^{1}$ Bloomsbury Institute of Intensive Care Medicine, University College London, London WC1E 6BT, UK

Full author information is available at the end of the article randomized controlled trials, databases and transcriptomic libraries have identified various endotypes or subphenotypes where outcomes may differ in response to fluid [3], statins [4] or steroids [5, 6]. Prospective trials are commencing using big data, bioinformatics or novel biomarkers to target patient subphenotypes in the hope that benefit will accrue in some and iatrogenic harm avoided in others (e.g. RHU RECORDS (Rapid rEcognition of CORticosteroiD resistant or sensitive Sepsis), ClinicalTrials.gov Identifier: NCT04280497).

Yet along comes a virus that sweeps the planet and we, comprising medical, scientific and industry communities, have reverted to type. Throw the kitchen sink, or rather, a factory load of kitchen sinks, at the patients and hope something works. Einstein posited that if he had an hour to solve a problem, he would spend 55 min thinking about the problem and 5 min thinking about solutions. With coronavirus disease 2019 (COVID-19) there has been barely any thought in the rush. A plethora of interventions, many with next-to-no scientific basis or even directly conflicting effects, have been trialled [7] or, worse still, simply given to patients on compassionate grounds [8]. These have been driven by bandwagons, media hype, availability and cost of a product, and/or a desperation to do something extra regardless of the risk of negative consequences that may not be readily apparent. At the time of writing, 2981 interventional trials on COVID-19 patients had been registered on the clinicaltrials.gov website, but only 415 (13.9\%) completed. A fifth (629) are large Phase III trials, a third of which are industry-led, but only 79 (12.6\%) have been completed. A worrying number of Phase III trials have not had prior Phase II assessments demonstrating preliminary safety and markers of efficacy. 
Many of the interventions are potently immunosuppressive yet systematic surveillance of adverse events and recording of long-term outcomes have largely been inadequate. This is even more relevant when the often prolonged hospitalisation of the most severely affected patients and longer-term complications related to severe acute respiratory distress syndrome (ARDS) and 'long Covid' are considered [9]. For example, significant 28-day mortality improvement with corticosteroids has only been shown in a single open-label trial [10, 11]; knowledge of safety and outcomes beyond 28 days still remain unknown for this and all other reported corticosteroid randomised controlled trials (RCTs) [11]. The largest survival benefit from dexamethasone in the RECOVERY study was achieved in those who were mechanically ventilated at enrolment, yet this subset only constituted a fifth of all patients enrolled and perhaps over a third of these patients were still in hospital at 28 days with ultimate fate unknown [10]. Steroids may hasten recovery in some patients but adversely affect others $[5,6]$. The increase in deaths (with a significant interaction test) in the enrolled patients who were not receiving oxygen at initiation of corticosteroids remains a still unexplained and significant safety concern. The impact on secondary infection rates is also unclear. Furthermore, long-duration corticosteroid therapy may be associated with protracted neuromuscular weakness, and more prolonged viral replication increasing genetic diversification [12, 13].

We have allowed usual standards of trial design and monitoring to slip using urgency and pragmatism as convenient excuses. While we sympathize with the challenges of performing high-quality randomised trials at short notice and at speed under highly stressful conditions, we do have to ask whether we have been remiss in not including placebo controls and not collecting more granular safety and survival data to better inform our interpretation of reported trials, or even a centralised registry collecting data from both uncompleted or unreported negative trials or compassionate use. The lack of medium- to long-term follow-up is also concerning. Furthermore, few studies have collected blood samples to assess the biological effects of these interventions and better identify the subphenotypes who may or may not benefit.

In 2018 the Nuffield Council of Bioethics identified the core challenge in balancing the interests of patients in accessing experimental treatments with the need to support innovation, yet ensuring sufficient safeguards to protect patients from potential harm(s) [14]. With COVID-19 disease, physicians have been under intense emotional pressure to offer interventions over and above standard of care. They have been spurred on by clinicians, scientists and industry with indistinct justifications for prescribing repurposed products. Patients and families have been desperate to grasp at remedies, unaware of any biological rationale or prior safety profiling, yet trusting of their attending clinicians. With compassionate use treatments, how often were patients or their families offered informed consent, involved in the decision making, or indeed even made aware of their use? In the cold light of day, will mistakes be acknowledged and lessons learnt?

One learnt lesson is clear in 2021: shortcutting science perpetuates ineffective and unsafe treatments. The randomized, double-blind, placebo-controlled trial with systematic and comprehensive collection of safety, biomarkers, short- and long-term survival outcomes, remains the most effective and ethical science to save lives. Is that feasible in the middle of a pandemic? Absolutely yes. Despite thousands of observational studies published on potential drugs against SARS-CoV-2, the only antiviral with significant clinical benefits in hospitalized patients with COVID-19 was discovered through a randomized double-blind placebo-controlled trial which enrolled over one thousand patients and was completed in just 58 days [15].

\section{Author details \\ ${ }^{1}$ Bloomsbury Institute of Intensive Care Medicine, University College London, London WC1E 6BT, UK. ${ }^{2}$ Division of Infectious Diseases, University of Nebraska Medical Center, Omaha, NE, USA.}

\section{Declarations}

Conflict of interest

MS: none. AK: none.

\section{Publisher's Note}

Springer Nature remains neutral with regard to jurisdictional claims in published maps and institutional affiliations.

Received: 22 April 2021 Accepted: 9 June 2021

Published online: 5 July 2021

References

1. Kalil AC, Johnson DW, Lisco SJ, Sun J (2017) Early goal-directed therapy for sepsis. Crit Care Med 45:607-614

2. Singer M, Glynne P (2005) Treating critical illness: the importance of first doing no harm. PLoS Med 2:e167

3. Famous KR, Delucchi K, Ware LB, Kangelaris KN, Liu KD, Thompson BT, Calfee CS, Network ARDS (2017) Acute respiratory distress syndrome subphenotypes respond differently to randomized fluid management strategy. Am J Respir Crit Care Med 195:331-338

4. Calfee CS, Delucchi KL, Sinha P, Matthay MA, Hackett J, Shankar-Hari M, McDowell C, Laffey JG, O'Kane CM, McAuley DF, Irish Critical Care Trials Group (2018) Acute respiratory distress syndrome subphenotypes and differential response to simvastatin: secondary analysis of a randomised controlled trial. Lancet Respir Med 2018(6):691-698

5. Antcliffe DB, Burnham KL, Al-Beidh F, Santhakumaran S, Brett SJ, Hinds CJ, Ashby D, Knight JC, Gordon AC (2019) Transcriptomic signatures in sepsis 
and a differential response to steroids. From the VANISH randomized trial. Am J Respir Crit Care Med 199:980-986

6. Wong HR, Hart KW, Lindsell CJ, Sweeney TE (2021) External corroboration that corticosteroids may be harmful to septic shock endotype A patients. Crit Care Med 49:e98-e101

7. Snow TAC, Singer M, Arulkumaran N (2020) Immunomodulators in COVID-19: two sides to every coin. Am J Respir Crit Care Med 202:1460-1462

8. Kalil AC (2020) Treating COVID-19-off-label drug use, compassionate use, and randomized clinical trials during pandemics. JAMA 2020(323):1897-1898

9. Nalbandian A, Sehgal K, Gupta A, Madhavan MV, McGroder C, Stevens JS, Cook JR, Nordvig AS, Shalev D, Sehrawat TS, Ahluwalia N, Bikdeli B, Dietz D, Der-Nigoghossian C, Liyanage-Don N, Rosner GF, Bernstein EJ, Mohan S, Beckley AA, Seres DS, Choueiri TK, Uriel N, Ausiello JC, Accili D, Freedberg DE, Baldwin M, Schwartz A, Brodie D, Garcia CK, Elkind MSV, Connors JM, Bilezikian JP, Landry DW, Wan EY (2021) Post-acute COVID-19 syndrome. Nat Med 27:601-615

10. RECOVERY Collaborative Group (2021) Dexamethasone in hospitalized patients with Covid-19. N Engl J Med 384:693-704

11. Chaudhuri D, Sasaki K, Karkar A, Sharif S, Lewis K, Mammen MJ, Alexander P, Ye Z, Lozano LEC, Munch MW, Perner A, Du B, Mbuagbaw L, Alhazzani W, Pastores SM, Marshall J, Lamontagne F, Annane D, Meduri GU,
Rochwerg B (2021) Corticosteroids in COVID-19 and non-COVID-19 ARDS: a systematic review and meta-analysis. Intensive Care Med 47:521-537

12. Li H, Chen C, Hu F, Wang J, Zhao Q, Gale RP, Liang Y (2020) Impact of corticosteroid therapy on outcomes of persons with SARS-CoV-2, SARS-CoV, or MERS-CoV infection: a systematic review and meta-analysis. Leukemia 34:1503-1511

13. Liu J, Zhang S, Dong X, Li Z, Xu Q, Feng H, Cai J, Huang S, Guo J, Zhang L, Chen Y, Zhu W, Du H, Liu Y, Wang T, Chen L, Wen Z, Annane D, Qu J, Chen D (2020) Corticosteroid treatment in severe COVID-19 patients with acute respiratory distress syndrome. J Clin Invest 130:6417-6428

14. Nuffield Council on Bioethics (2018) Patient access to experimental treatments. https://www.nuffieldbioethics.org/publications/experiment al-treatments. Accessed 20 Apr 2021

15. Beigel JH, Tomashek KM, Dodd LE, Mehta AK, Zingman BS, Kalil AC, Hohmann E, Chu HY, Luetkemeyer A, Kline S, Lopez de Castilla D, Finberg RW, Dierberg K, Tapson V, Hsieh L, Patterson TF, Paredes R, Sweeney DA, Short WR, Touloumi G, Lye DC, Ohmagari N, Oh MD, Ruiz-Palacios GM, Benfield T, Fätkenheuer G, Kortepeter MG, Atmar RL, Creech CB, Lundgren J, Babiker AG, Pett S, Neaton JD, Burgess TH, Bonnett T, Green M, Makowski M, Osinusi A, Nayak S, Lane HC, ACTT-1 Study Group Members (2020) Remdesivir for the treatment of Covid-19-final report. N Engl J Med 383:1813-1826 